Technical Note

\title{
Comparison of Vertically Integrated Fluxes of Atmospheric Water Vapor According to Satellite Radiothermovision, Radiosondes, and Reanalysis
}

\author{
Dmitry Ermakov ${ }^{1,2, *}$, Alexey Kuzmin ${ }^{2}$, Evgeny Pashinov ${ }^{2}$, Victor Sterlyadkin ${ }^{3}$, Andrey Chernushich ${ }^{1}$ \\ and Eugene Sharkov ${ }^{2}$ \\ 1 Fryazino Department of Kotelnikov Instiute of Radioengineering and Electorincs, \\ Russian Academy of Sciences, Vvedenskogo Sq. 1, 141120 Fryazino, Russia; andrey@ire216.msk.su \\ 2 Space Research Institute, Russian Academy of Sciences, Profsoyuznaya Str. 84/32, 117997 Moscow, Russia; \\ alexey.kuzmin@asp.iki.rssi.ru (A.K.); pashinov@iki.rssi.ru (E.P.); easharkov@iki.rssi.ru (E.S.) \\ 3 Moscow Institute of Radiotechniki Electroniki i Avtomatiki (MIREA)—Russian Technological University, \\ 119454 Moscow, Russia; sterlyadkin@mirea.ru \\ * Correspondence: dima@ire.rssi.ru
}

Citation: Ermakov, D.; Kuzmin, A.; Pashinov, E.; Sterlyadkin, V.; Chernushich, A.; Sharkov, E. Comparison of Vertically Integrated Fluxes of Atmospheric Water Vapor According to Satellite Radiothermovision, Radiosondes, and Reanalysis. Remote Sens. 2021, 13, 1639. https://doi.org/10.3390/ rs13091639

Academic Editors: Soudani Kamel and Dimitrios Katsanos

Received: 14 February 2021

Accepted: 19 April 2021

Published: 22 April 2021

Publisher's Note: MDPI stays neutral with regard to jurisdictional claims in published maps and institutional affiliations.

Copyright: (c) 2021 by the authors. Licensee MDPI, Basel, Switzerland. This article is an open access article distributed under the terms and conditions of the Creative Commons Attribution (CC BY) license (https:/ / creativecommons.org/licenses/by/ $4.0 /)$.

\begin{abstract}
The atmospheric advection of water vapor is one of the most important components of the planetary hydrological cycle. Radiosondes are a means for regular observations of water vapor fluxes. However, their data are sparse in space and time. A more complete picture is provided by reanalysis assimilating these data. However, a statistically representative check of the reanalysis estimates of the water vapor fluxes far from regularly operating weather stations is difficult. The previously proposed and developed method of satellite radiothermovision makes it possible to reconstruct the vertically integrated advective water vapor fluxes from satellite microwave radiometry. In this work, for the first time, the results of direct comparisons of long ( 5 year) time series of zonal vertically integrated daily water vapor fluxes based on the data of radiosondes, reanalysis, and satellite radiothermovision are performed and presented. It is shown that all the data series are statistically reliably correlated (at a confidence level of 0.995). The regression factor between the fluxes from reanalysis and satellite radiothermovision was close to 1 , but with a noticeable bias (the latter were about $60 \mathrm{~kg} /(\mathrm{m} \cdot \mathrm{s})$ less on average). Grounds are given for the hypothesis that calculations based on satellite radiothermovision mainly characterize water vapor fluxes in the lower troposphere (up to heights of about $4 \mathrm{~km}$ ). Its verification, as well as the analysis of the noted cases of violation of the correlation between the fluxes from satellite radiothermovision and reanalysis, requires further research.
\end{abstract}

Keywords: advection of water vapor; calculation of latent heat fluxes; radiosondes; reanalysis; satellite radiothermovision

\section{Introduction}

The atmospheric advection of water vapor is one of the most important components of the planetary hydrological cycle. It transports atmospheric moisture and latent heat from the tropics to high latitudes and from the oceans inland, largely determining the Earth's climate [1]. The average rate of this transport on climatic time scales is determined by the parameters of the global atmospheric circulation. In turn, climatic changes can cause changes in these parameters, weakening, strengthening, and/or deforming the circulation cells [2]. Thus, over the past several decades, the analysis of remote sensing data has revealed the effect of the "tropics widening", which is not quite adequately reproduced by climatic models [2,3]. Therefore, an extremely urgent task of remote sensing of the Earth is to clarify and detail the global advection of atmospheric moisture and its regular monitoring. Another intensively developed area of research is the search for key conditions for the origin and development of catastrophic processes in the Earth's atmosphere [4]. The emergence of theoretical concepts of self-organization of spiral turbulence into stable 
large-scale structures has significantly increased the requirements for knowledge of the space-time distributions of the main geophysical parameters of the atmosphere.

The satellite radiothermovision of atmospheric processes [5] is an approach that allows for the retrieval of the dynamics of atmospheric moisture (primarily the water vapor) in terms of vector fields of advection speed. The calculations are closed with respect to the data of satellite radiometric measurements and are based on pyramidal optical flow analysis. A typical case is the solution of the two-dimensional task. The fields of integral atmospheric parameters (such as total precipitable water) for succeeding days of measurements are considered boundary conditions, and the algorithm searches for the parameters of a simple kinematic model that smoothly transform the earlier field into the later one ([5], Chapter 3). This, in particular, allows for the estimation of the intermediate atmospheric states and for matching them against the results of independent retrievals. Such tests were made by analogy to the work [6], and proved, on average, the slightly better accuracy of our (satellite radiothermovision) approach compared to that of the method in [6].

Having the fields of both the total precipitable water and its effective advection speed (as an output of the kinematic model applied), one can easily estimate advective water vapor fluxes integrated over the height of the atmosphere by multiplying those two fields. It should be noted that, to date, as far as we know, satellite radiothermovision is the only approach allowing one to calculate these values directly from satellite remote data. Such an approach has been successfully applied to the analysis of the dynamics of mesoscale ([5], Chapter 4) and synoptic ([5], Chapter 5) atmospheric processes, and to the calculation of a number of parameters of the global atmospheric circulation ([5], Chapter 6).

However, the accuracy of the retrievals of the advection field has only been checked indirectly - through the accuracy of the interpolated precipitable water fields. In this paper, for the first time, a direct comparison is made. To this end, we used three types of products. The first is the water vapor flux obtained from satellite radiothermovision by multiplying the retrieved values of total precipitable water and effective advection speed. The second is the ready-to-use water vapor flux from the reanalysis data. The third is the flux obtained by numerical integration of meteosonde data over the atmospheric height. All three product types were calculated as long time series for the selected locations. Their comparison was made in reference to Liu and Tang's work [7], including correlation and regression analysis. The rest of the paper is organized as follows: Section 2 gives an introduction to the previous work in the field, Section 3 describes the data and methods used, and Section 4 discusses the results of the work, followed by concluding remarks in Section 5 .

\section{Previous Work}

For a direct calculation of the horizontal flux of water vapor (or latent heat) at a point with given geographic coordinates, it is necessary to take the integral of the product of the vertical profiles of humidity and wind speed from the surface to the upper boundary of the atmosphere. Therefore, it seems most natural to use radiosonde measurements, which contain all the necessary information. An early systematic application of this approach was demonstrated by Starr and White [8], in which an attempt was made to calculate zonally averaged meridional water vapor fluxes in the northern hemisphere. This approach was further developed and applied to the analysis of global and regional water balance in subsequent works [9-13].

However, the specificity of radiosonde measurements has certain drawbacks from the point of view of global climatology tasks. A network of meteorological stations where such measurements are made, especially over the ocean, is still quite rare. Measurement sessions are carried out, as a rule, twice a day, and sometimes less often. Each session consists of a single launch of the radiosondes, e.g., Durre et al. [14]. Therefore, generally speaking, there remain questions both to the accuracy and reproducibility of measurements and to the space-time scales in relation to which these measurements can be considered representative. The greatest errors should be expected in difficult meteorological conditions, for example, when a tropical cyclone or powerful front passes near a meteorological station. 
Another option is to use the results of reanalysis-calculations based on numerical weather models that assimilate, among others, radiosonde data. This approach is attractive because of the detailed information available: a few climatological variables, including the zonal and meridional components of the water vapor flux, are calculated on a regular grid with a step of about 0.25 geographic degrees and a time sampling of about $1 \mathrm{~h} \mathrm{[15].}$ However, it should be borne in mind that this information is not independent of radiosonde measurements, since the assimilation technique involves the construction of a smoothed solution that reproduces the data of actual observations as closely as possible. In this regard, it is interesting to note that the discrepancies between the daily mean flux values according to the radiosonde and reanalysis data turn out to be higher than they are between the corresponding instantaneous values. This, again, raises the question of the representativeness of both types of data from the point of view of climatological problems and the need to develop alternative calculation methods.

Satellite measurements provide much more complete coverage of the Earth than the sparse data of radiosondes. However, the latter give explicit information on the vertical profiles of atmospheric parameters such as humidity and wind speed, while the retrieval of those from satellite data remains a challenge. The fields of total precipitable water (TPW), $W$, can be reliably retrieved; however, obtaining detailed and robust vertical profiles of humidity and wind is still problematic, especially in the atmospheric layer below $700 \mathrm{hPa}$, where the main amount of atmospheric moisture is concentrated. A recent work by Posselt et al. [16] is almost a unique example of the quantitative assessment of atmospheric motion vector uncertainties under various atmospheric states and observation conditions. However, the tracking method applied there could resolve water vapor advection rates with not less than $4 \mathrm{~m} / \mathrm{s}$ discretization (in particular, winds less than $4 \mathrm{~m} / \mathrm{s}$ were not detectable). The method was a type of a standard pattern matching technique that automatically estimated displacements of "features" in the "water vapor fields" [16] retrieved from subsequent measurements of infrared (primarily) or high-frequency microwave [17] satellite sounders. The method's performance was subject to various sources of errors, such as inaccurate retrievals of humidity profiles and heights of the "features", and wrong or uncertain matches within a tracking window due to the single-window approach.

In the works by Liu, Liu, and Tang $[7,18]$, the concept of the effective advection rate $\mathbf{u}_{\mathbf{e}}$, defined as the ratio of the vertically integrated water vapor flux $\Theta$ to the TPW value $W$, was introduced:

$$
\begin{gathered}
\mathbf{u}_{\mathbf{e}}=\boldsymbol{\Theta} / W \\
\boldsymbol{\Theta}=\frac{1}{g} \int_{0}^{p_{s}} q \mathbf{u} d p \\
W=\frac{1}{g} \int_{0}^{p_{s}} q d p
\end{gathered}
$$

where $g$ is the acceleration due to gravity, $p$ is the pressure, $p_{s}$ is the pressure at the surface, and $q$ and $\mathbf{u}$ are the specific humidity and wind speed at the level corresponding to the pressure $p$, respectively. It is assumed that $\mathbf{u}_{\mathrm{e}}$ is strongly correlated with the surface wind velocity $\mathbf{u}_{\mathrm{s}}$, the values of which can be obtained, for example, from scatterometric measurements. This opens the fundamental possibility of calculating $\Theta$ from a known $W$ and $\mathbf{u}_{\mathrm{s}}$. In [7], an attempt was made to empirically establish a quantitative relationship between $\mathbf{u}_{\mathrm{e}}$ and $\mathbf{u}_{\mathrm{s}}$ using an artificial neural network trained on a sample of radiosonde data and reanalysis estimations.

The described approach assumes that there are synchronous or quasi-synchronous measurements with a scatterometer (to reconstruct $\mathbf{u}_{\mathrm{s}}$ ) and a multichannel radiometer (to reconstruct $W$ ), which imposes certain restrictions on the use of satellite information. In [7], QuikScat and TMI data were used, respectively, which made it possible to obtain estimates of $\Theta$ in the latitude band from $40 \mathrm{~S}$ to $40 \mathrm{~N}$ with a spatial resolution of 
0.25 geographic degrees in the time interval from August 1999 to August 2003 and with a frequency of twice a day. It should be emphasized that, although, at the stage of processing satellite information, the method can be considered independent of other measurements, the neural network restoring the key parameter $\mathbf{u}_{\mathrm{e}}$ was trained using the same data types with which the results were later compared (radiosondes and reanalysis). Considering also that, from a methodological point of view, a neural network is a kind of "black box", it seems difficult to assess what contribution to the detected discrepancies was made by different types of errors: errors in processed satellite information, learning errors, errors in radiosonde and reanalysis data of the training and test sets, and the inaccuracy of the model assuming an unambiguous relationship between $\mathbf{u}_{\mathrm{e}}$ and $\mathbf{u}_{\mathrm{s}}$.

Within the framework of satellite radiothermovision [5], an alternative interpolation method for calculating $\mathbf{u}_{\mathrm{e}}$, completely closed with respect to the data of satellite radiometric measurements, was proposed based on optical flow analysis. The calculation is carried out on a global regular coordinate grid with a step of 0.25 geographic degrees and makes it possible to reconstruct the $W$ and $\mathbf{u}_{\mathrm{e}}$ fields with a frequency of 4-8 times a day. The purpose of this work is to preliminarily estimate the accuracy of $\mathbf{u}_{\mathrm{e}}$ reconstruction using a technique similar to that used by Liu and Tang [7].

\section{Data and Methods}

It should be noted that the reanalysis estimations of vapor fluxes demonstrate an extremely high correlation with those obtained from radiosonde data (see Section 4). For this reason, they can both be considered as almost momentary and very local. On the contrary, satellite radiothermovision suggests a unique approach to retrieving vapor fluxes from satellite data, giving spatiotemporally averaged estimations (within $0.25^{\circ}$ cell and several hours). Comparing momentary and local values versus spatiotemporally averaged ones has additional methodological difficulties because, in the present work, we aimed to demonstrate a principally good quantitative agreement of the datasets when additional disturbing effects (such as closely passing tropical cyclones) are minimized. Such "laminar" conditions are met in the southern Atlantic, far from the intertropical convergence zone (ICZ). In contrast to them are the conditions within the ICZ, e.g., in the western Pacific. This determines the choice of the principal locations of observations.

\subsection{Observation Points and Time Intervals}

The coordinates of the meteorological stations selected for data analysis, as well as the coordinates of the closest nodes of the reanalysis grid and those of satellite radiothermovision, are given in Table 1.

Table 1. Coordinates of the selected meteorological stations (MS) and corresponding grid nodes of reanalysis (RA) and satellite radiothermovision (SR).

\begin{tabular}{cccccccc}
\hline & \multicolumn{2}{c}{ MS } & \multicolumn{2}{c}{ RA } & \multicolumn{3}{c}{ SR } \\
\hline $\mathbf{N}$ & ID & Lat & Lon & Lat & Lon & Lat & Lon \\
\hline 1 & SHM00068906 & -40.35 & -9.88 & -40.25 & -10.00 & -40.38 & -9.87 \\
2 & SHM00061901 & -15.94 & -5.67 & -16.00 & -5.75 & -15.88 & -5.62 \\
3 & RMM00091366 & 8.73 & 167.73 & 8.75 & 167.75 & 8.38 & 167.88 \\
4 & RMM00091376 & 7.07 & 171.29 & 7.00 & 171.25 & 6.87 & 171.38 \\
\hline
\end{tabular}

The locations of the selected stations are also indicated in Figure 1. It can be seen that Stations 1 and 2 are located in the southern Atlantic, the basin being unaffected by strong mesoscale atmospheric phenomena such as tropical cyclones. Station 1 is outside the tropics, while Station 2 is within the tropical belt. 


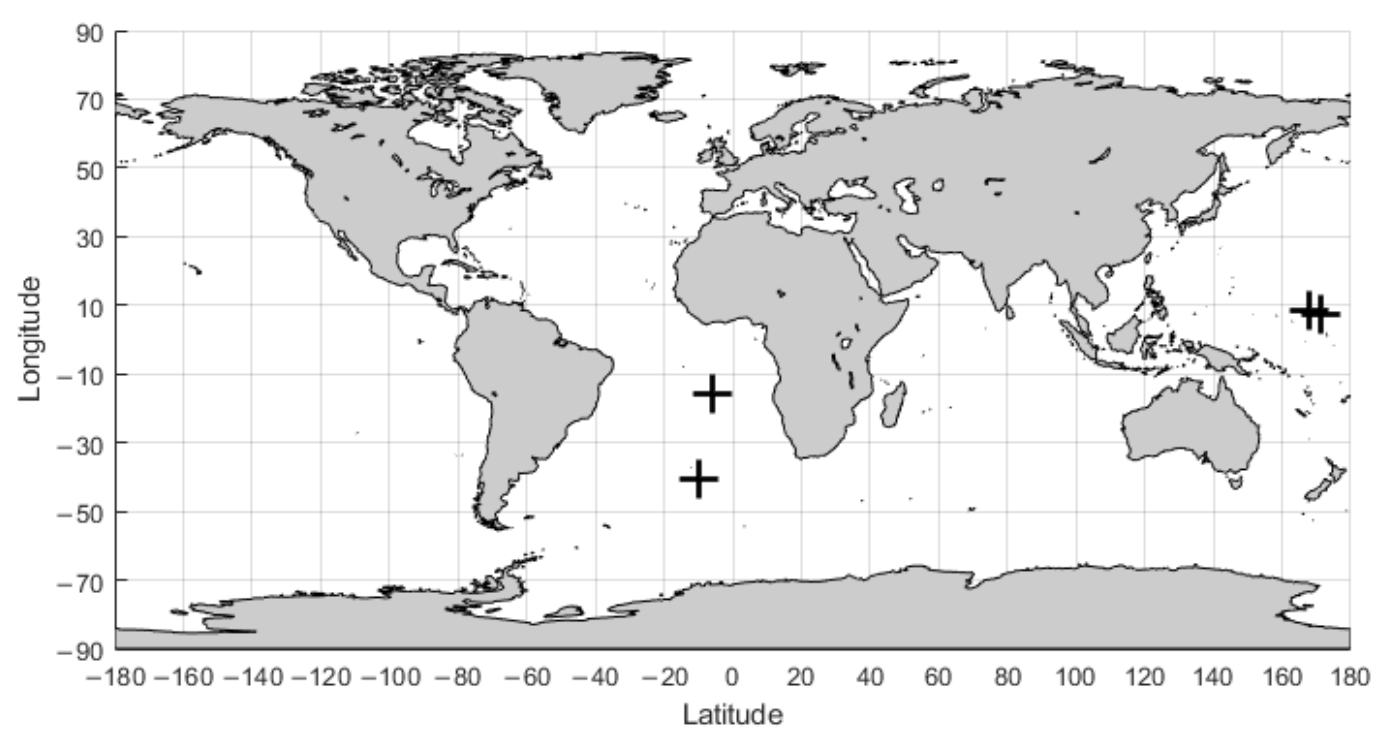

Figure 1. Locations of the selected weather stations indicated by + . Numbers next to + correspond to those in Table 1.

On the contrary, Stations 3 and 4 are in the northwest Pacific, within the ICZ. This basin is strongly affected by strong mesoscale atmospheric phenomena such as typhoons.

It should be noted that, in some cases, the grid nodes of the reanalysis and satellite radiothermovision were not the closest possible ones. This is due to the fact that satellite radiothermovision data are not available at nodes located over large areas of land or close to them. In these cases, the nearest grid nodes in which the data were available were found.

Data were analyzed for five years of observations (2015-2019). The work is illustrated mainly by the results of the analysis of data corresponding to the position of Station 1 (Table 1). Details regarding other data are discussed separately.

\subsection{Satellite Radiothermovision}

The technique for retrieving water vapor fluxes using satellite radiothermovision is described in detail in [5], Chapter 3. Its essence is in the dynamic analysis of the products of processing daily satellite radiometric measurements (SSMIS and WindSat), which is based on a modified method of motion estimation/compensation (see, for example, [19,20]). As a result, it is possible to reconstruct, on a regular grid with a 0.25 -degree step, the full-coverage TPW fields over the ocean with a time sampling of $1.5-3 \mathrm{~h}$, as well as corresponding vector displacement fields describing the motions of the elements of the TPW field in the time intervals between consecutive observations with a corresponding time sampling of 3-6 h [5]. After geometric correction and normalization, these displacement fields are recalculated into the vector fields of the effective (integrated over the height of the atmosphere) water vapor advection velocity $\mathbf{u}_{\mathrm{e}}$. As a result, the flux at the selected observation point is calculated by

$$
\Theta_{\mathbf{s}}=W \mathbf{u}_{\mathrm{e}} .
$$

The data fields of $W$ and $\mathbf{u}_{\mathrm{e}}$ with $6 \mathrm{~h}$ time sampling used in this work are available on the geoportal of satellite radiothermovision (https: / / fireras.su/tpw, accessed on 20 April 2021), see also [5], Chapter 8.

\subsection{Radiosondes}

The Integrated Global Radiosonde Archive (IGRA) v2 database was used as a source of radiosonde data [14]. The IGRA database contains radiosonde data from over 2700 weather stations located around the world from 1938 to the present day. Radiosonde measurements include information on the vertical profile of the geopotential height, pressure, temperature, dew point deficit, relative humidity, wind speed, and direction. Most weather stations take measurements twice a day at 00 and 12 UTC, and some well-equipped stations make 
additional launches at $03,06,15$, and 18 UTC. Approximately $70 \%$ of radiosondes launched since at least the 1960s provide data up to 100 mbar altitudes at more than 20 levels [14]. According to these characteristics, the IGRA database is suitable for a wide range of scientific tasks, including the validation of remote sensing data.

The radiosonde data were used in this work to calculate the advective fluxes of water vapor and the subsequent comparison with other sources. The calculation of the zonal flux was carried out according to the following equation:

$$
\Theta_{m}=\int_{h_{\min }}^{h_{\max }} \rho(h) u(h) d h
$$

where $h$ is the geopotential height $(\mathrm{m}), \rho(h)$ is the profile of the absolute atmospheric humidity $\left(\mathrm{kg} / \mathrm{m}^{3}\right)$, and $u(h)$ is the profile of the zonal component of the wind speed $(\mathrm{m} / \mathrm{s})$. The meridional flow can be calculated in a similar way. For this, in Formula (5), it is necessary to replace the zonal component of the wind speed $u(h)$ with the meridional one $v(h)$.

\subsection{Reanalysis}

The reanalysis data were used as the primary source of data on atmospheric water vapor fluxes with which the radiothermovision data were compared. We used ERA5 reanalysis, which is the latest generation of ECMWF reanalysis [15]. It contains global fields of two-dimensional and three-dimensional distributions of various geophysical characteristics on a regular grid of coordinates with a spatial resolution of $0.25^{\circ} \times 0.25^{\circ}$ and a time resolution of $1 \mathrm{~h}$. In particular, the zonal component of the atmospheric water vapor flux is represented in the ERA5 data directly in the variable named the vertical integral of the eastward water vapor flux. The reanalysis data was accessed through the Copernicus Climate Data Store service. For processing, we selected data from the reanalysis fields at the grid points closest to the meteorological stations.

\subsection{Comparison Method}

For comparison, the calculated fluxes were selected at the nodes of the satellite radiothermovision and reanalysis grids that were as close as possible to the location of the meteorological stations. In the case when the calculation by the method of satellite radiothermovision at the nearest node was impossible due to the influence of the land, one of the nearest neighboring nodes was chosen instead, where the calculation could be performed. The coordinates of the meteorological stations and the corresponding nodes of the satellite radiothermovision and reanalysis grids are given in Table 1 and in Figure 1. Comparison of the zonal components of the fluxes was carried out, since they, on average, are several (up to five) times higher than the meridional fluxes [21], and one should expect larger variations of these fluxes, resolved by each of the methods.

Continuous time series of calculated flux values for the years 2015-2019 were built. To combine the data from all sources in time and compensate for possible differences associated with intraday variations, time averaging was performed. A preliminary analysis of the data series was carried out with daily averaging, which gives the most detailed picture of the atmospheric dynamics. Averaging was also used over longer time intervals, in particular, five-day intervals, by analogy with the work by Liu and Tang [7], and up to 21-day intervals, to investigate the proximity of estimations at various synoptical time scales.

\section{Results and Discussion}

Figure 2 compares the results of calculating water vapor fluxes for 2015-2019 according to satellite radiothermovision, $\Theta_{\mathrm{s}}$, reanalysis, $\Theta_{\mathrm{r}}$, and radiosondes, $\Theta_{\mathrm{m}}$. The series $\Theta_{\mathrm{r}}$ and $\Theta_{\mathrm{m}}$ are not independent and demonstrate high cross-correlation everywhere. The main interest is the extent to which the series $\Theta_{\mathrm{S}}$ and $\Theta_{\mathrm{r}}$ agree depending on the availability and 
quality of radiosonde data; therefore, in addition to the indicated data series, the figure shows the characteristics of radiosonde sessions: the number of sessions per day and the pressure range covered by them.

Figure 2 contains five panels illustrating the data series for the years 2015-2019. Each panel stands for one particular year. The upper part of each panel provides insight on the radiosonde sessions: the yellow stepped bar shows the number of sessions per day (from 0 to 2), and the upper blue bar shows the covered pressure range (in $\mathrm{hPa}$ ). At the bottom of each panel, there are plots of the fluxes $\Theta_{\mathrm{s}}$ (blue line), $\Theta_{\mathrm{r}}$ (orange line), and $\Theta_{\mathrm{m}}$ (gray line) with daily averaging (scale in $\mathrm{kg} /(\mathrm{m} \cdot \mathrm{s})$ to the left of the plots). Positive flux values correspond to the eastward direction. The horizontal axis is the number of the day of the year. The panels are ordered from top to bottom by year number from 2015 to 2019, inclusively.

As can be seen in the graphs in Figure 2, the results of independent calculations on satellite radiothermovision and reanalysis are generally consistent with each other and reflect the general trends in variations in zonal water vapor fluxes, especially on large time scales. At the same time, significant differences (of the order of magnitude of the fluxes themselves) may appear in daily estimates. Of particular interest is 2019, during the second half of which, no radiosondes were launched.

The correlation coefficients between the $\Theta_{\mathrm{s}}$ and $\Theta_{\mathrm{r}}$ series for each year from 2015 to 2019 separately (orange line) and the corresponding total number of radiosondes sessions for these years (gray bars) are shown in Figure 3a. The figure also shows the correlation coefficient between the full five-year data series $\Theta_{\mathrm{S}}$ and $\Theta_{\mathrm{r}}$, equal to 0.655 (blue line). It can be seen that the correlation between the series $\Theta_{\mathrm{s}}$ and $\Theta_{\mathrm{r}}$ deteriorated significantly in 2019: only in this year did it turn out to be significantly below the level of 0.655 (approximately $0.60)$, while in other years it was about 0.66 or higher. However, it should be noted that the correlation coefficient for the first half of 2019 (while radiosonde measurements were carried out) was slightly lower (0.59) than for the second half (0.62). When smoothing the five-year $\Theta_{\mathrm{s}}$ and $\Theta_{\mathrm{r}}$ series in a sliding five-day window, the correlation coefficient between them increases to 0.71 (red line). The statistical analysis proved that the correlation is reliable at (at least) a 0.995 confidence level.

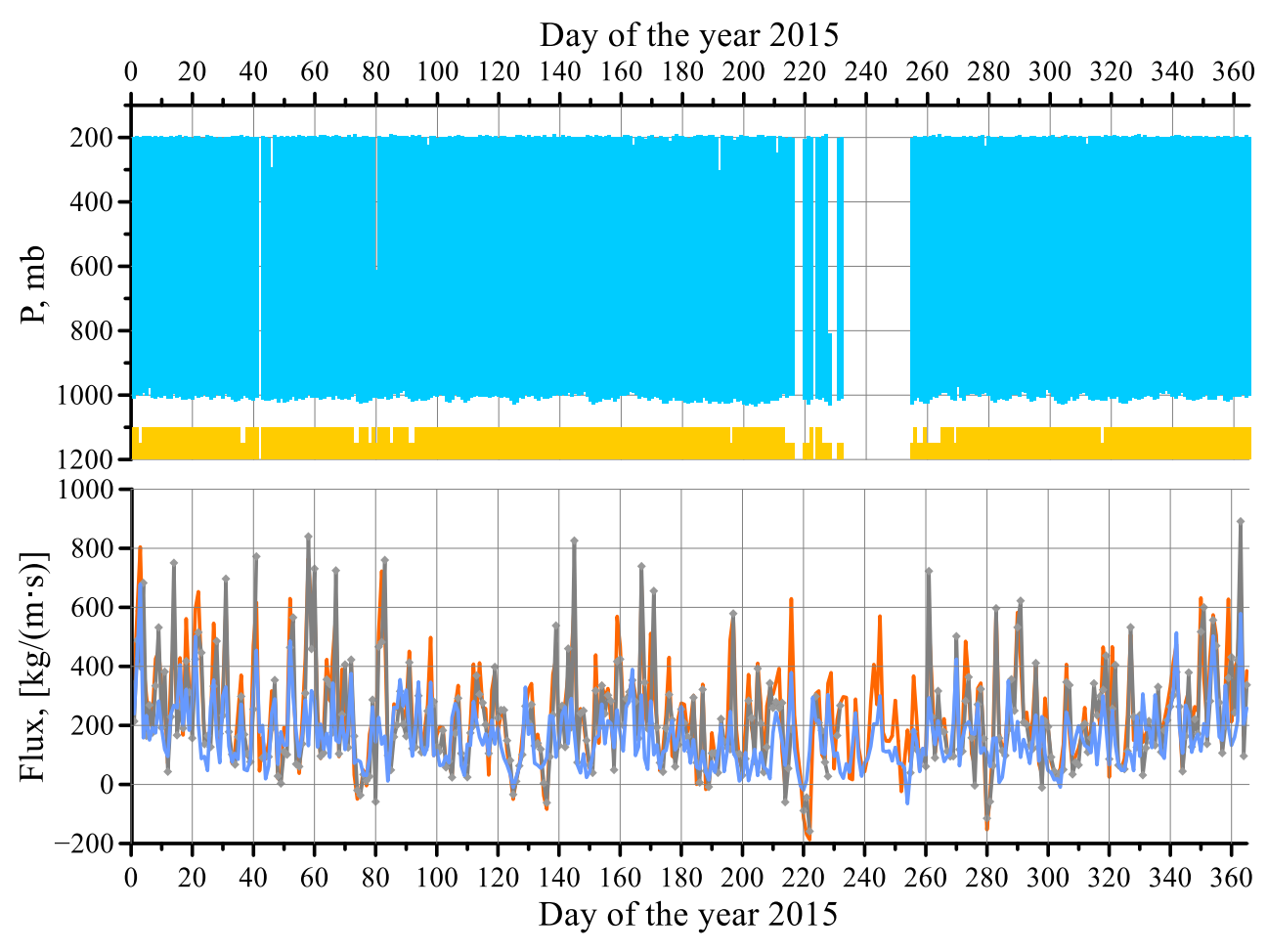

Figure 2. Cont. 
Day of the year 2016
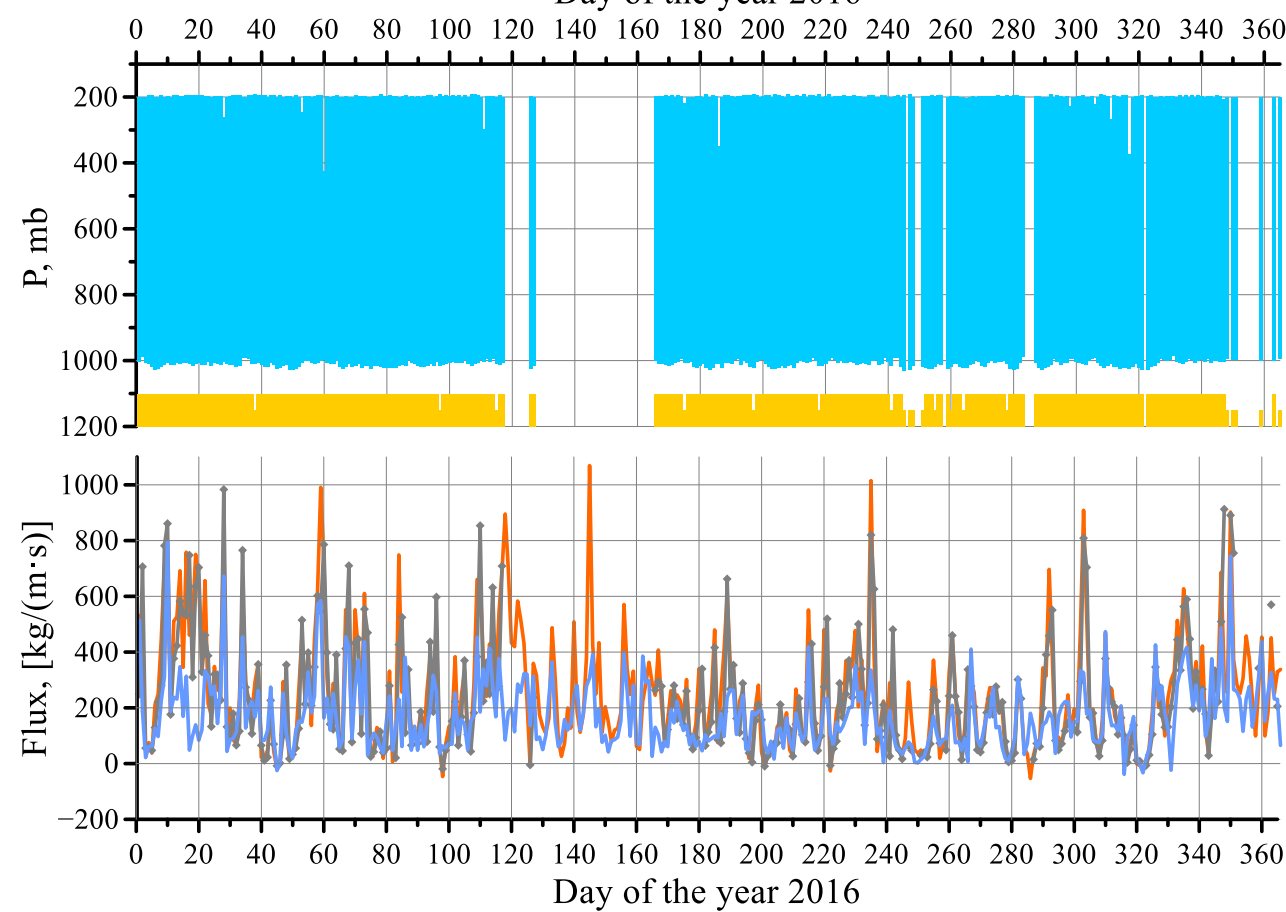

Day of the year 2017

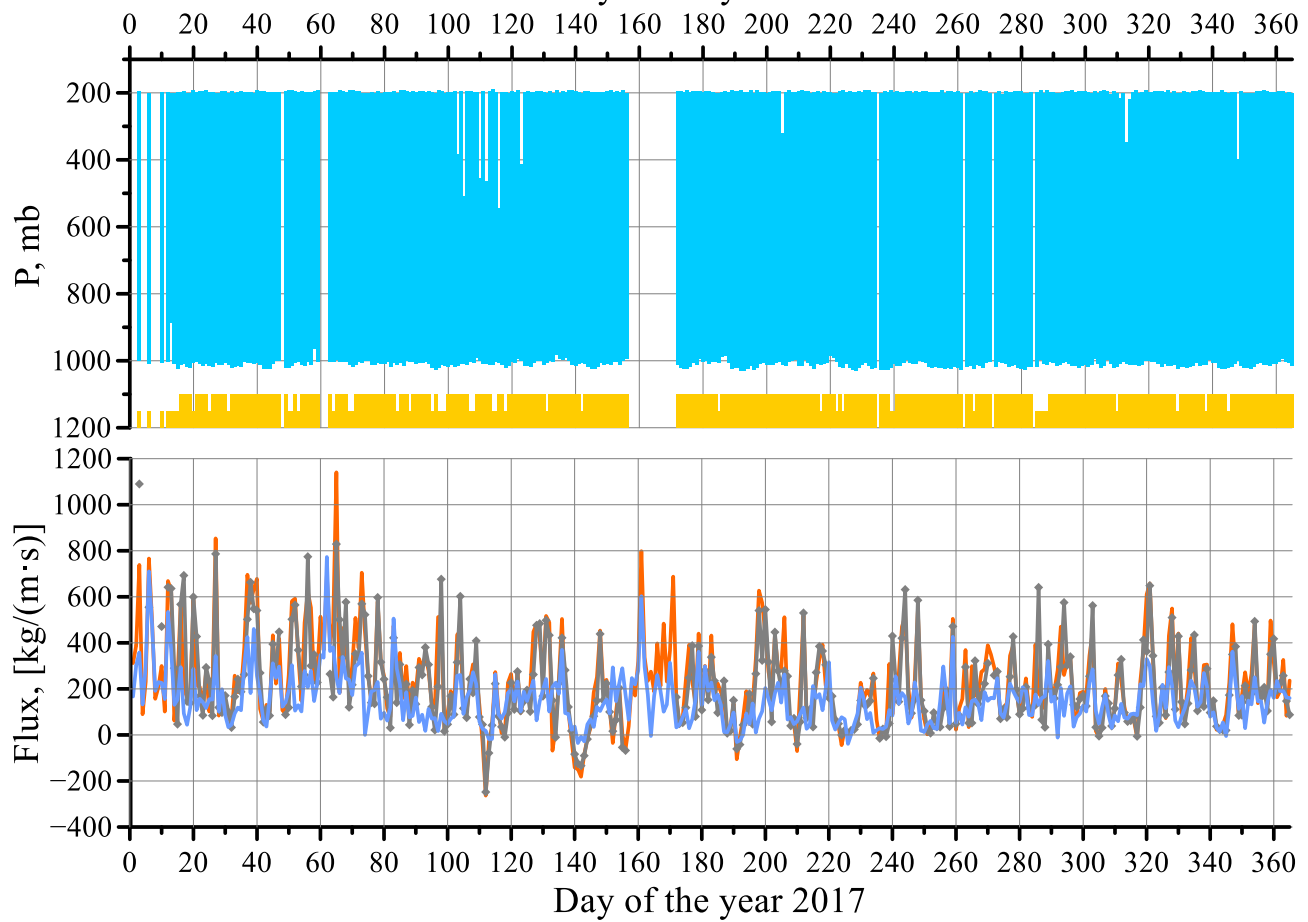

Figure 2. Cont. 

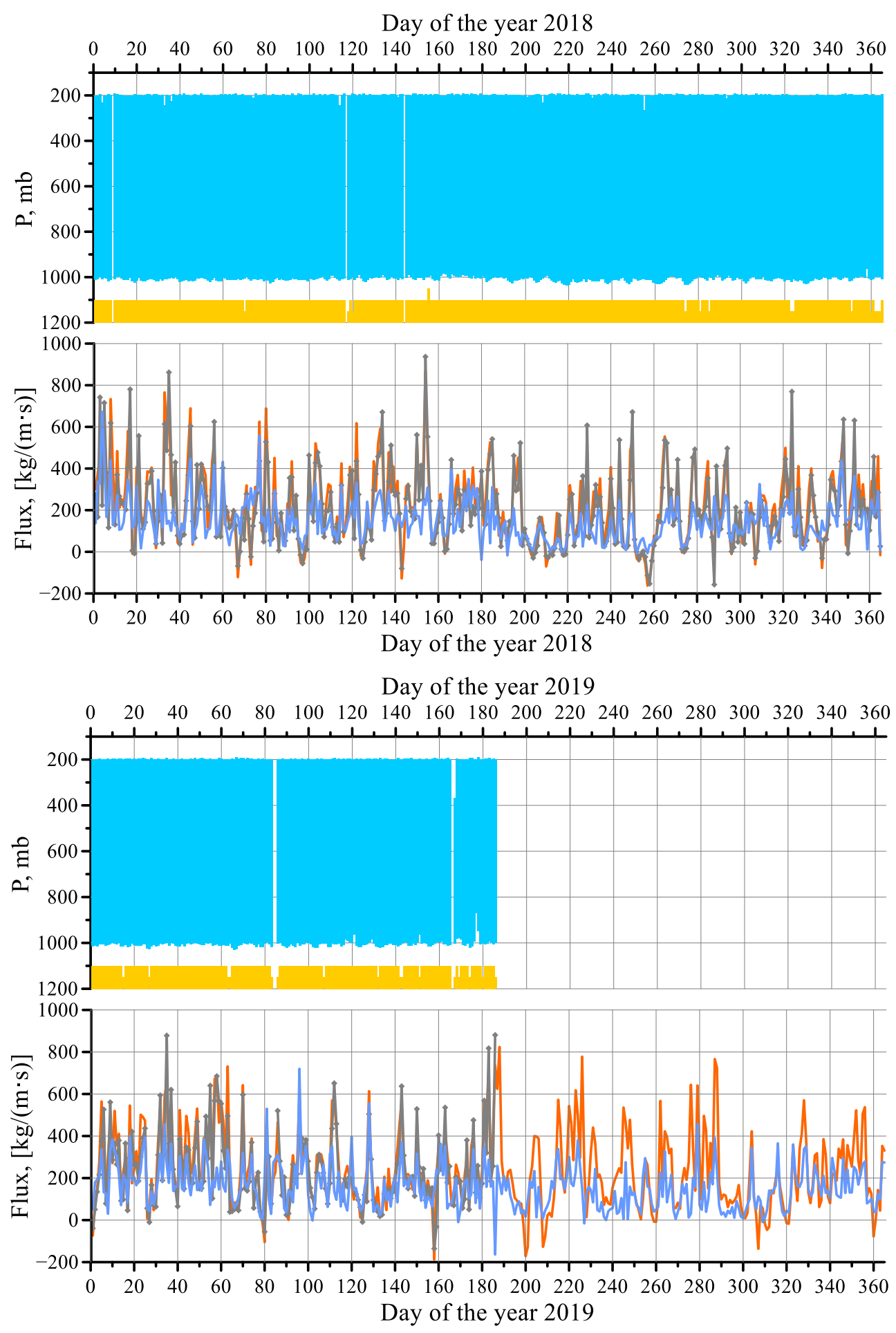

Figure 2. Comparison of the series of calculated zonal fluxes $\Theta_{\mathrm{s}}$ (blue), $\Theta_{\mathrm{r}}$ (orange), and $\Theta_{\mathrm{m}}$ (gray) near Station 1 (see Table 1 and Figure 1) for the years 2015-2019, along with the pressure range covered by radiosondes (light blue), and the daily number of radiosonde measurements (yellow), see comments in the text.

The general trend of an increase in the correlation coefficient with an increase in the time interval of averaging is shown in Figure 3b. It plots the values of the correlation between the $\Theta_{\mathrm{s}}$ and $\Theta_{\mathrm{r}}$ series with smoothing in the intervals of $3,5,7, \ldots, 21$ days (by horizontal axis) for different stations. The number next to the curve corresponds to the number of the weather station in Table 1 . It can be seen that the correlation basically 
increases with the size of the time window. For Stations 1 and 2 in the Atlantic, it grows to about 0.8 , but it is remarkably lower for Stations 3 and 4 within the Pacific intertropical convergence zone. This might be due to the disturbing effect of powerful mesoscale processes (such as tropical cyclones).

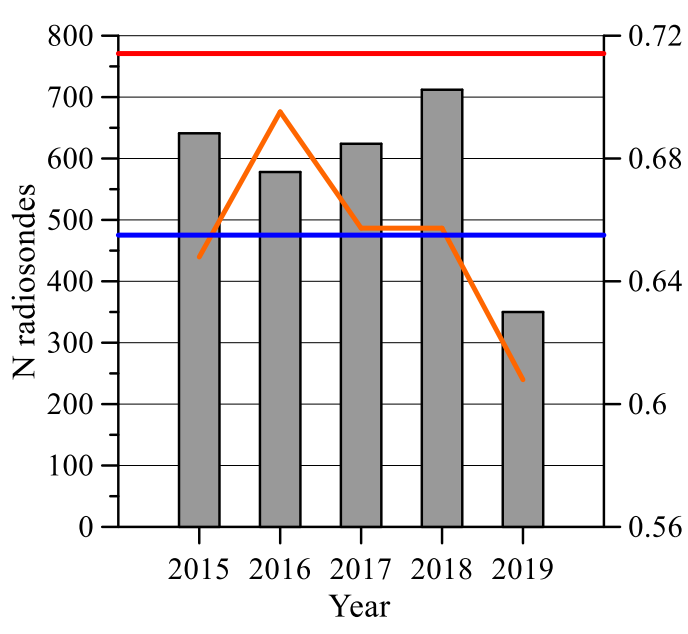

(a)

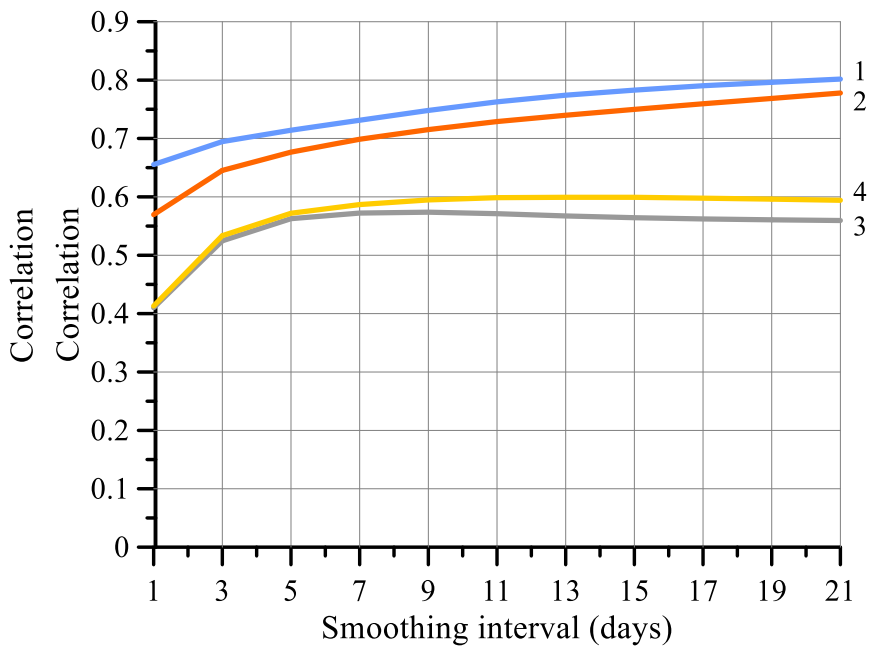

(b)

Figure 3. Correlation analysis between the $\Theta_{\mathrm{S}}$ and $\Theta_{\mathrm{r}}$ time series. (a) Correlation of yearly series from 2015 to 2019 (orange line) and the number of radiosonde measurements per year (gray bars); (b) correlation of the 5-year time series as a function of the smoothing window size (1-21 days). Numbers next to the curves correspond to the weather stations in Table 1, see comments in the text.

Figure $4 \mathrm{a}$ illustrates the $\Theta_{\mathrm{s}}$ vs. $\Theta_{\mathrm{r}}$ scatterplots for the entire five-year interval (blue circles and blue regression line) and for the first and second half of 2019 (orange squares and gray triangles, respectively). It can be seen that the linear regressions of $\Theta_{\mathrm{S}}$ by $\Theta_{\mathrm{r}}$ have slope coefficients close to 1 with an accuracy of about $10 \%$, except for the case of the second half of 2019, when this coefficient exceeds 1.2. However, in all cases, the regressions have a noticeable bias. Regression equations are given in the plot. Figure $4 \mathrm{~b}$ compares the average annual values of $\Theta_{\mathrm{s}}$ (blue), $\Theta_{\mathrm{r}}$ (orange), and $\Theta_{\mathrm{m}}$ (gray) and their standard deviations (vertical bars).

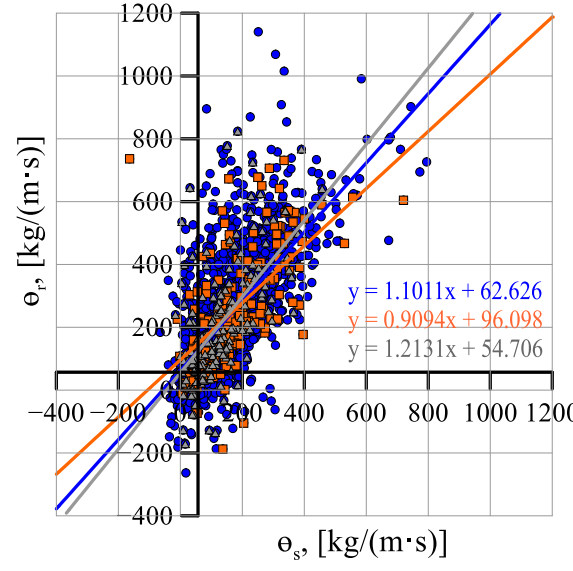

(a)

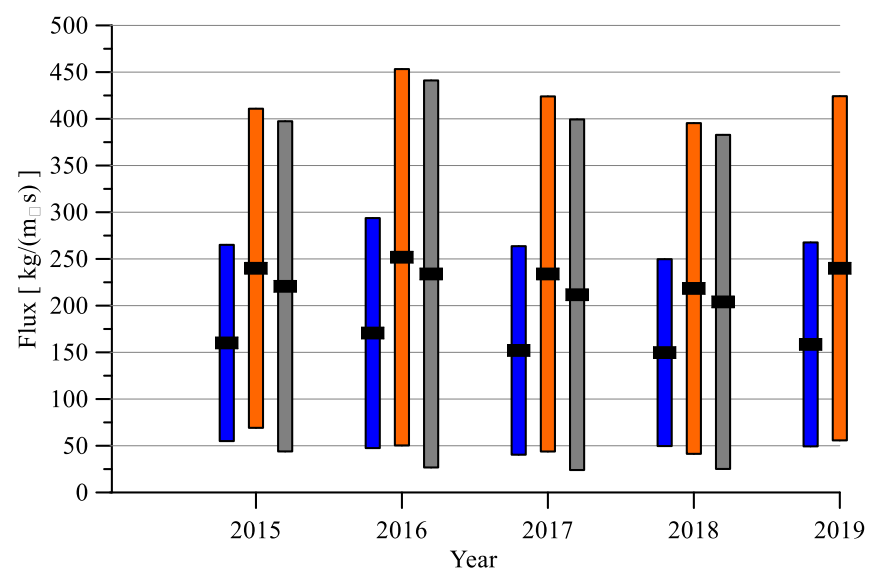

(b)

Figure 4. (a) Scatterplot of $\Theta_{\mathrm{r}}$ (vertical axis) by $\Theta_{\mathrm{s}}$ (horizontal axis) and flux values in $\mathrm{kg} /(\mathrm{m} \cdot \mathrm{s})$. Positive values correspond to the eastward direction. Regression lines and equations for the 5-year series (blue), the first half of 2019 (orange), and the second half of 2019 (gray); (b) annual average flux values (horizontal stripes) and their annual rms variations (vertical bars: $\Theta_{\mathrm{s}}$ - blue, $\Theta_{\mathrm{r}}$-orange, $\Theta_{\mathrm{m}}$ - gray), see comments in the text. 
The calculation of the annual average values of the fluxes $\Theta_{\mathrm{S}}$ and $\Theta_{\mathrm{r}}$ (Figure $4 \mathrm{~b}$ ) confirms the presence of a systematic shift in the series of values by about $80 \mathrm{~kg} /(\mathrm{m} \cdot \mathrm{s})$, which practically does not change over the years under consideration and is significantly lower than the average annual standard deviation of the fluxes. It should be noted that a similar, but smaller, bias (about $20 \mathrm{~kg} /(\mathrm{m} \cdot \mathrm{s})$ ) also exists between the values of the fluxes $\Theta_{\mathrm{m}}$ and $\Theta_{\mathrm{r}}$ (the average annual values of $\Theta_{\mathrm{r}}$ are higher in both cases). This made it possible to formulate a hypothesis explaining the observed systematic discrepancy in the values of $\Theta_{\mathrm{m}}, \Theta_{\mathrm{s}}$, and $\Theta_{\mathrm{r}}$. The hypothesis was that each type of data characterizes the latent heat flux in its range of atmospheric heights, from the surface to some effective upper boundary. In the case of meteorological data, this boundary is the maximum height of the probe rise. For reanalysis, this boundary turns out to be higher, since, in fact, an integral flux is modeled from zero to an infinitely high horizon. For satellite radiothermovision, this boundary, on the contrary, is obviously located much lower, since it is in the lower troposphere where the most significant features of the spatial structure of the TPW field are formed. In support of this hypothesis are the results of comparing the latent heat fluxes calculated from the radiosonde data for the maximum ascent heights of $10 \mathrm{~km}, \Theta_{\mathrm{m}}$, and the $\Theta^{\prime}$ m fluxes calculated from the same data with the maximum height limitation by a fixed $h_{\text {max }}$ limit (see Figure 5).

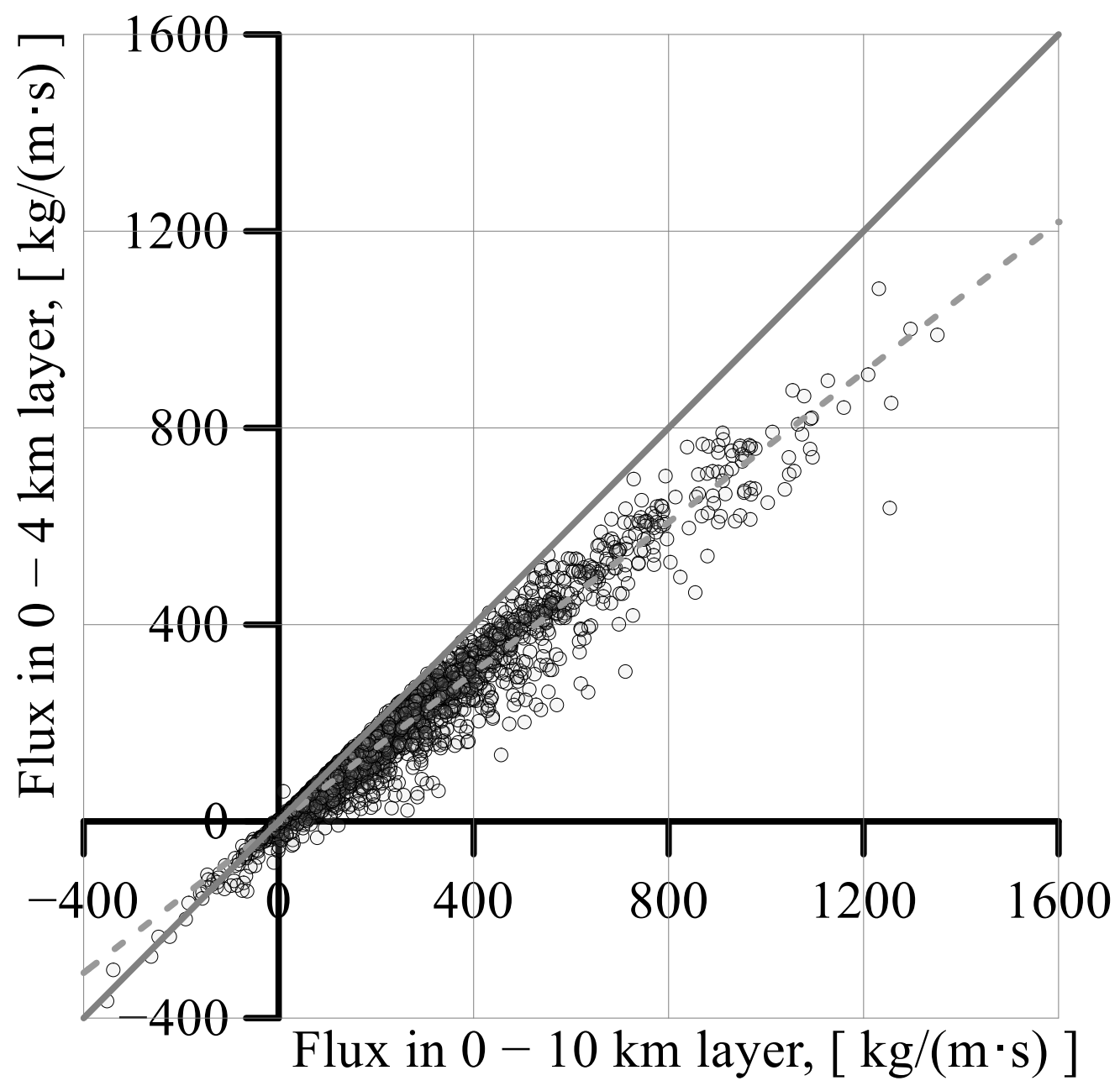

Figure 5. Scatterplot of $\Theta_{m}$ vs. $\Theta_{m}^{\prime}$ values (circles). Dotted gray line-linear regression $\left(\Theta_{m}=1.3 \Theta_{m}^{\prime}+17\right)$; $\mathrm{R}=0.96)$, solid gray line-1:1 line.

Figure 5 shows an example of such a comparison for $h_{\max }=4000 \mathrm{~m}$. As can be seen, the values $\Theta_{m}$ and $\Theta_{m}^{\prime}$ are linearly related to each other with a correlation coefficient close to 1. At the same time, the average difference between $\Theta_{m}$ and $\Theta^{\prime} m$ calculated over the 
shown samples is about $68 \mathrm{~kg} /(\mathrm{m} \cdot \mathrm{s})$, which is very close to those differences demonstrated in Figure $4 \mathrm{~b}$ between $\Theta_{\mathrm{m}}$ and $\Theta^{\prime}$. The hypothesis made is consistent with the results of Wimmers and Velden [6]. They showed that the evolution of the total precipitable water field can be satisfactorily described by the advection field built as a weighted sum of wind speeds at three horizons within the lower troposphere. This indicates that the algorithm of satellite radiothermovision must be mainly sensitive to the vapor fluxes within the lower troposphere as well. In [6], Wimmers and Velden used different (empirically found) sets of weighting coefficients for various latitudinal zones, which helped to virtually account for variations in humidity and wind vertical profiles. By arbitrarily changing the $h_{\text {max }}$ limit, one can obtain the best correlation between the $\Theta_{\mathrm{s}}$ and $\Theta_{\mathrm{m}}$ data series for a particular location. However, it is currently quite problematic to independently argue for such a choice. A thorough spatiotemporal analysis, which is within the scope of our future research, can shed light on this problem.

In order to characterize the overall discrepancy between $\Theta_{\mathrm{s}}$ and $\Theta_{\mathrm{r}}$, we also calculated the SD and RMSE values according to the following equations:

$$
\begin{gathered}
S D=\sqrt{\frac{1}{N-1} \sum_{i=1}^{N}\left|E_{i}-\bar{E}\right|^{2}} \\
R M S E=\sqrt{\frac{1}{N} \sum_{i=1}^{N}\left|E_{i}\right|^{2}} \\
\bar{E}=\frac{1}{N} \sum_{i=1}^{N} E_{i}
\end{gathered}
$$

where $E_{i}=\Theta_{\mathrm{r}}-\Theta_{\mathrm{s}}$ for the $i$-th day in the sample, and $N$ is the sample size (total number of days in the years 2015-2019). We also calculated $S D^{\prime}$ and $R M S E^{\prime}$ for the discrepancies $E_{i}^{\prime}{ }_{i}=\Theta_{\mathrm{r}}-\Theta^{\prime}{ }_{\mathrm{S}}$, where $\Theta_{\mathrm{s}}^{\prime}$ is the "linearly corrected" value of $\Theta_{\mathrm{s}}$ according to the previously obtained regression of $\Theta_{\mathrm{r}}$ by $\Theta_{\mathrm{s}}$, e.g., for Station 1 (see Figure $4 \mathrm{a}$ ), $\Theta^{\prime}{ }_{\mathrm{s}}=1.10 \Theta_{\mathrm{s}}+62.63$. Values of $S D, R M S E, S D^{\prime}$, and $R M S E^{\prime}$ for all the considered locations (see Table 1) are given in Table 2.

Table 2. SD/SD'; RMSE/RMSE' (kg/m.s); and correlation, R, between 5 year series of daily $\Theta_{\mathrm{r}}$ and $\Theta_{\mathrm{s}}$ values and of those smoothed in a 21 day sliding window for the 4 stations listed in Table 1.

\begin{tabular}{ccccccccc}
\hline & Station & & \multicolumn{3}{c}{ Daily Series } & \multicolumn{2}{c}{ 21-Day Smoothed Series } \\
\hline $\mathbf{N}$ & Lat & Lon & SD/SD' & RMSE/RMSE' & R & SD/SD' $^{\prime}$ & RMSE/RMSE' $^{\prime}$ R $^{\prime}$ \\
\hline 1 & -40.35 & -9.88 & $140.31 / 83.24$ & $160.80 / 83.22$ & 0.69 & $43.15 / 26.36$ & $89.46 / 26.35$ \\
2 & -15.94 & -5.67 & $66.42 / 59.78$ & $83.65 / 59.76$ & 0.66 & $25.71 / 25.04$ & $25.71 / 25.03$ & 0.78 \\
3 & 8.73 & 167.73 & $188.63 / 139.40$ & $189.71 / 139.36$ & 0.52 & $106.18 / 58.03$ & $106.18 / 58.02$ & 0.56 \\
4 & 7.07 & 171.29 & $193.81 / 148.37$ & $194.83 / 148.33$ & 0.53 & $108.93 / 65.05$ & $108.90 / 65.03$ & 0.59 \\
\hline
\end{tabular}

It can be seen that, on average, the discrepancies between $\Theta_{\mathrm{s}}$ and $\Theta_{\mathrm{r}}$ are much lower for Stations 1 and (especially) 2, but for all stations, they significantly decrease after smoothing the time series. As mentioned before, $\Theta_{\mathrm{s}}$ is highly correlated with almost momentary and local $\Theta_{\mathrm{m}}$ data. Smoothing partly compensates for different spatiotemporal resolutions of the $\Theta_{\mathrm{s}}$ and $\Theta_{\mathrm{r}}$ series, increasing their correlation and decreasing discrepancies.

\section{Conclusions}

The reconstruction of atmospheric latent heat fluxes from actual satellite observations is of great importance in short-term weather forecasting, the analysis and forecasting of the development of extreme weather events, and studies of general atmospheric circulation and climatic variations. The previously proposed techniques based on the analysis of optical flux are mainly applicable to measurements in the visible and IR spectral ranges from 
geostationary satellites, and provide information mainly on atmospheric movements above $700-600 \mathrm{hPa}$ (about 3-4 km). Satellite radiothermovision offers a unique approach to remote data processing for reconstructing fluxes integrated over the height of the atmosphere, where a decisive role is played by movements in the lower troposphere, which are poorly reconstructed in other approaches.

In this paper, for the first time, a direct comparison was performed of vapor fluxes according to satellite radiothermovision with those from radiosondes and reanalysis. Fiveyear time series with daily sampling over selected locations were analyzed. It should be noted that, while radiosonde data are strictly localized in time and space (and the reanalysis is highly correlated with them due to the assimilation algorithm), the satellite radiothermovision instead characterizes fluxes averaged over the cells $0.25^{\circ}$ by $0.25^{\circ}$, and over time intervals of several hours. In these conditions, the best match between the considered series of fluxes corresponded to the location of the weather station in the mid-latitudes of the southern Atlantic, where the disturbing effects of powerful mesoscale processes are almost absent. For this location, the correlation between the series was found to be 0.655 and to continuously grow up to 0.8 when smoothing the time series with a sliding window of up to 21 days (however, for all the considered locations, the fluxes were found to be statistically and reliably correlated at a confidence level of at least 0.995).

For the first time, the parameters of linear regression between vapor fluxes from reanalysis, $\Theta_{r}$, and those directly retrieved from satellite measurements with the satellite radiothermovision approach were obtained. For the primary location considered (Station 1 in Table 1), the regression was $\Theta_{\mathrm{r}}=1.10 \Theta_{\mathrm{s}}+62.63$. Thus, it appeared to have a factor of about 1.1, but a noticeable bias (the latter were about $60 \mathrm{~kg} /(\mathrm{m} \cdot \mathrm{s})$ less on average). Grounds are given for the hypothesis that calculations based on satellite radiothermovision mainly characterize water vapor fluxes in the lower troposphere (up to heights of about $4 \mathrm{~km}$, the upper border depending on the moisture profile and wind speed). For this reason, the efficiency of this method is the highest in the study of atmospheric processes, in which the lower atmosphere, for example, atmospheric rivers, plays a decisive role. At the same time, the high correlation of latent heat fluxes, integrated over the height of the atmosphere and calculated in a certain lower layer (Figure 5), makes it possible, based on the satellite radiothermovision approach, to judge the rates of latent heat advection in the entire atmosphere. In this case, however, as can be seen in Figure 4a, some correction of the absolute values may be required. This circumstance may partly explain some of the features of the latitudinal distribution of meridional latent heat fluxes (e.g., the width of the Hadley cell being too large), obtained earlier using the satellite radiothermovision method ([5], Chapter 7).

In conclusion, it should be noted once again that the reanalysis estimations of vapor fluxes demonstrate an extremely high correlation with those obtained from radiosonde data. For this reason, they can both be considered almost momentary and very local. On the contrary, satellite radiothermovision suggests a unique approach to retrieving vapor fluxes from satellite data, giving spatiotemporally averaged estimations (within $0.25^{\circ}$ cells and several hours). This causes additional methodological difficulties in their comparison, since the research was divided into several steps. The main aim of the present work was to demonstrate principally good quantitative agreement between the two datasets when additional disturbing effects (such as closely passing tropical cyclones) are minimized. Our future research plans include a thorough spatiotemporal analysis of the correlation and discrepancies between vapor fluxes from satellite radiothermovision and reanalysis, which could indicate the limits of the applicability of our approach and yield key information on the upper boundary $h_{\max }$ of the lower troposphere layer, which is virtually characterized by the estimations according to satellite radiothermovision.

It should be noted that the methodology designed and tested in this work opens an important opportunity to globally analyze the reliability not only of the estimates of vapor fluxes retrieved from satellite radiothermovision, but also of those from reanalysis. Significant discrepancies between $\Theta_{\mathrm{r}}$ and $\Theta_{\mathrm{S}}$ may indicate the effect of local short-time at- 
mospheric disturbances on radiosonde measurements and, consequently, on the reanalysis estimates. While the latter are considered to be average characteristics within $0.25^{\circ}$ cells, they demonstrate an almost $100 \%$ correlation with the radiosondes. On the contrary, the estimates from satellite radiothermovision have a spatial resolution of $0.25^{\circ}$, and, as such, naturally provide a single effective value for each $0.25^{\circ}$ cell. Thus, further widespread spatiotemporal comparison of $\Theta_{\mathrm{r}}$ and $\Theta_{\mathrm{S}}$ using the presented technique with thorough statistical analysis of their discrepancies could be of great value and is included in our ongoing research plans.

Author Contributions: Conceptualization, D.E., A.K. and E.S.; methodology, D.E. and V.S.; software, A.C. and E.P.; writing-original draft preparation, D.E. and E.P.; writing—review and editing, D.E. and A.K.; supervision, project administration, E.S. All authors have read and agreed to the published version of the manuscript.

Funding: This research received no external funding.

Institutional Review Board Statement: Not applicable.

Informed Consent Statement: Not applicable.

Data Availability Statement: The data of satellite radiothermovision calculations used to estimate vapor fluxes from satellite remote data are available on the geoportal of satellite radiothermovision (https: / fireras.su/tpw, accessed on 20 April 2021).

Acknowledgments: The authors are grateful for the ERA5 reanalysis produced by the European Centre for Medium-Range Weather Forecasts (ECMWF) and for the radiosonde data provided by the National Centers for Environmental Information Integrated Global Radiosonde Archive (IGRA). The authors would also like to thank all the anonymous reviewers for their valuable comments and remarks.

Conflicts of Interest: The authors declare no conflict of interest.

\section{References}

1. Barry, R.G.; Chorley, R.J. Atmosphere, Weather and Climate, 8th ed.; Taylor and Praxis Group: London, UK; New York, NY, USA, 2003; p. 421.

2. Reichler, T. Changes in the atmospheric circulation as indicator of climate change. In Climate Change: Observed Impacts on Planet Earth; Trevor, M.L., Ed.; Elsevier: Amsterdam, The Netherlands, 2009; pp. 145-164.

3. Lu, J.; Deser, C.; Reichler, T. Cause of the widening of the tropical belt since 1958. Geophys. Res. Lett. 2009, 36, L03803. [CrossRef]

4. Sharkov, E.A. Global Tropical Cyclogenesis, 2nd ed.; Springer: Berlin/Heidelberg, Germany, 2012; p. 604.

5. Ermakov, D.M. Satellite Radiothermovision of Atmospheric Processes: Method and Applications; Springer: Cham, Switzerland, 2021; p. 199. [CrossRef]

6. Wimmers, A.J.; Velden, C.S. Seamless advective blending of total precipitable water retrievals from polar orbiting satellites. J. Appl. Meteorol. Clim. 2011, 50, 1024-1036. [CrossRef]

7. Liu, W.T.; Tang, W. Estimating moisture transport over ocean using space-based observations. J. Geophys. Res. 2005, 110 , D10101. [CrossRef]

8. Starr, V.P.; White, R.M. Direct measurement of the hemispheric poleward flux of water vapor. J. Mar. Res. 1955, 14, 217-225.

9. Starr, V.P.; Peixoto, J.P. On the global balance of water vapor and the hydrology of deserts. Tellus 1958, 10, 188-194. [CrossRef]

10. Rasmusson, E.M. Atmospheric water vapor transport and the water balance of North America: Part I. Characteristics of the water vapor flux field. Mon. Wea. Rev. 1967, 95, 403-426. [CrossRef]

11. Rosen, R.D.; Salstein, D.A.; Peixoto, J.P. Streamfunction analysis of interannual variability in large-scale water vapor flux. Mon. Weather Rev. 1979, 107, 1682-1684. [CrossRef]

12. Bryan, F.; Oort, A. Seasonal variation of the global water balance based on aerological data. J. Geophys. Res. 1984, 89, 11717-11730. [CrossRef]

13. Chen, T.-C. Global water vapor flux and maintenance during FGGE. Mon. Weather Rev. 1985, 113, 1801-1819. [CrossRef]

14. Durre, I.; Vose, R.S.; Wuertz, D.B. Overview of the integrated global radiosonde archive. J. Clim. 2006, 19, 53-68. [CrossRef]

15. Hersbach, H.; Bell, B.; Berrisford, P.; Hirahara, S.; Horányi, A.; Muñoz-Sabater, J.; Nicolas, J.; Peubey, C.; Radu, R.; Schepers, D.; et al. The ERA5 global reanalysis. Q. J. R. Meteorol. Soc. 2020, 146, 1999-2049. [CrossRef]

16. Posselt, D.J.; Wu, L.; Mueller, K.; Huang, L.; Irion, F.W.; Brown, S.; Su, H.; Santek, D.; Velden, C.S. Quantitative assessment of state-dependent atmospheric motion vector uncertainties. J. Appl. Meteorol. Climatol. 2019, 58, 2479-2495. [CrossRef] 
17. Limbrightsen, B.; Van Dang, H.; Turk, F.J.; Hristova-Veleva, S.M.; Su, H.; Wen, Y. All-Weather tropospheric 3-D wind from microwave sounders. IEEE J. Sel. Top. Appl. Earth Obs. Remote Sens. 2018, 11, 1949-1956. [CrossRef]

18. Liu, W.T. Moisture and latent heat flux variabilities in the Tropical Pacific derived from satellite data. J. Geophys. Res. 1988, 93, 6749-6760. [CrossRef]

19. Anandan, P. A computational framework and an algorithm for the measurement of visual motion. Int. J. Comp. Vis. 1989, 2, 283-310. [CrossRef]

20. Richardson, I.E.G.H. 264 and MPEG-4 Video Compression; John Wiley \& Sons Ltd.: Chichester, UK, 2003; p. 306.

21. Palmén, E.; Newton, C.W. Atmospheric Circulation Systems: Their Structural and Physical Interpretation; Academic Press: New York, NY, USA, 1969; p. 603. 